\title{
Investigation of convective heat transfer coefficient and initial temperature of waxy crude oil on the formation of voids
}

\author{
Girma T. Chala ${ }^{1 *}$, Shaharin A. Sulaiman², Azuraien Japper-Jaafar ${ }^{2}$, Wan Ahmad \\ Kamil Wan Abdullah ${ }^{3}$ \\ ${ }^{1}$ Department of Mechanical Engineering, INTI International University, Pesiaran \\ Perdana bbn, 71800 Nilai, Negeri Sembilan, Malaysia \\ *Email: girma.chala@newinti.edu.my \\ Phone: +60143956537 \\ ${ }^{2}$ Department of Mechanical Engineering, Universiti Teknologi PETRONAS, Bandar Seri \\ Iskandar, 31750 Tronoh, Perak, Malaysia \\ ${ }^{3}$ Department of Radiology, Hospital Universiti Sains Malaysia, 16150 Kubang Kerian, \\ Kelantan, Malaysia
}

\begin{abstract}
This paper presents the convective heat transfer coefficient of waxy crude oil while undergoing cooling and reports the influence of initial temperature on the intra-gel void formation. A flow loop rig was used to cool down waxy crude oil to the same end temperature while varying the initial temperature to observe the effects of initial temperature on the voids formed. The convective heat transfer coefficient and heat transfer rate of waxy crude oil subjected to cooling were calculated. It was observed that the heat transfer rate and the convective heat transfer coefficient of waxy crude oil below the wax appearance temperature were much lower than that of the Newtonian liquid crude oil owing to the wax crystal formation entrapping some liquid crude oil within it, below which the formation of voids is eminent. In addition, it was found that lower initial temperatures tend to form higher void volumes near pipe walls and in the entire pipe with a maximum change in void volume of $0.9 \%$ observed between the maximum and the minimum initial temperature tested. The insignificant influence of initial temperature on intra-gel void formation was also observed as the waxes are liquid above the wax appearance temperature.
\end{abstract}

Keywords: Waxy crude oil; Gas voids; Convective heat transfer coefficient; Initial temperature.

\section{INTRODUCTION}

Worldwide waxy crude oil production at offshore fields has increased and accounts for about one third of the world oil production in the last decade [1]. The production rate has increased swiftly since its first production in the 1940s owing to the depletion of production at onshore fields. The production of crude oil from deep and ultra-deep waters is expected to make up the majority of the supply for our energy needs in the near future, which in turn requires investigations to alleviate problems encountered during transportation [2-4]. Waxy crude oil at offshore fields is mainly known for its high wax content. As the ambient temperature at the seabed is far lower than the pour point temperature of waxy crude oil, small amounts of wax tend to initiate the gelation of waxy crude oil, with three phase changes occurring: precipitation, deposition and gelation. 
Aiyejina et al. [5] reported that the deposition of waxes in pipelines carrying waxy crude oil was a complex phenomenon, which depends on the composition, pressure and temperature, heat and mass transfer, and phase interactions, which include solid-solid and solid-liquid interactions. Economides et al. [6] conducted a laboratory test and heat transfer analysis on waxy crude oil under cold atmospheric conditions that resulted in alteration of the sample behaviour and rheological properties owing to heat loss to the surroundings.

The thermodynamic properties of waxy crude oil address the states of waxes in waxy crude oil and the phases of samples under cooling mode. The thermal behaviour, which basically relies on the temperature of the waxy crude oil, has been a key parameter in understanding the wax-phase behaviour of waxy crude oil. The relationship between temperature and viscosity, for instance, has been a key factor in defining the Newtonian and non-Newtonian regions of waxy crude oils. Golczynski et al. [7] pointed out the thermal behaviour of waxy crude oil following a long shut down, after which the restarting pressure became much higher than it was during steady flow conditions. The various phase changes of waxy crude oil gel because of heating and cooling processes would predict and determine gel conditions undergoing the restart-up processes. It was mentioned that the heat transfer prior to gel formation affecting the thermal history and production rate (restart flow rate) determined the temperature profile ahead of restarting.

Restarting the gelled waxy crude oil in pipelines resting on the seabed remains a challenge and the conventional equation for restart pressure over-predicts its values [8]. The formation of voids in wax-oil gel was reported to make the waxy crude oil fluid compressible, which would make the restart pressure and pipeline design parameters lower than the estimated values from the conventional equation. As a result of thermal shrinkage of waxy crude oil during cooling, the formation of intra-gel voids is eminent [8-10]. Many research papers also recommended the understating of thermal shrinkage and the resulting gas voids formation to predict the restart pressure as accurately as possible [11]. Xiaokai et al. [12] illustrated the importance of considering the heat transfer calculation in the process of restarting, including physical properties of gelled crude oil during phase changes while cooling. However, there are no research studies reported that show the convective heat transfer coefficient of waxy crude oil while undergoing cooling and the effects of initial temperature on the voids in waxy crude oil gel. The objective of the current study was, therefore, to study the convective heat transfer coefficient of waxy crude oil during void formation and the effect of initial temperature on the intra-gel voids formed. This would outline how waxy crude oil behaves during the formation of intra-gel voids and estimate the influence of initial temperature on the formation of voids.

\section{METHODS AND MATERIALS}

\section{Experimental Setup and Techniques}

Figure 1 shows the flow loop rig used to produce a gel for a magnetic resonance imaging (MRI) scan. A waxy crude oil tank and a test section simulate the reservoir or well and subsea bed conditions at offshore fields, respectively. Waxy crude oil was cooled down to the same end temperature of $15^{\circ} \mathrm{C}$ while varying the initial temperatures to observe the effects of initial temperature on the intra-gel void formation. The heat dissipated from the waxy crude oil subjected to cooling was calculated from the temperature profile versus time of cooling obtained during the experiments. The start temperatures were $80{ }^{\circ} \mathrm{C}, 70$ ${ }^{\circ} \mathrm{C}, 60{ }^{\circ} \mathrm{C}$ and $50{ }^{\circ} \mathrm{C}$, well above the wax appearance temperature to erase any thermal and shear histories. All the gelled samples at the same end temperatures were scanned 
using the MRI technique shown in Figure 2. Experimental details for the initial temperature are depicted in Table 1. Figure 3 shows the initial temperature profiles of waxy crude oil while undergoing cooling in the cold reservoir. The variation in the cooling time of different initial temperatures was found to be insignificant as they are in the Newtonian region with the liquefied waxes. The effects of initial temperature on the voids near the pipe wall and core were then analysed and reported.

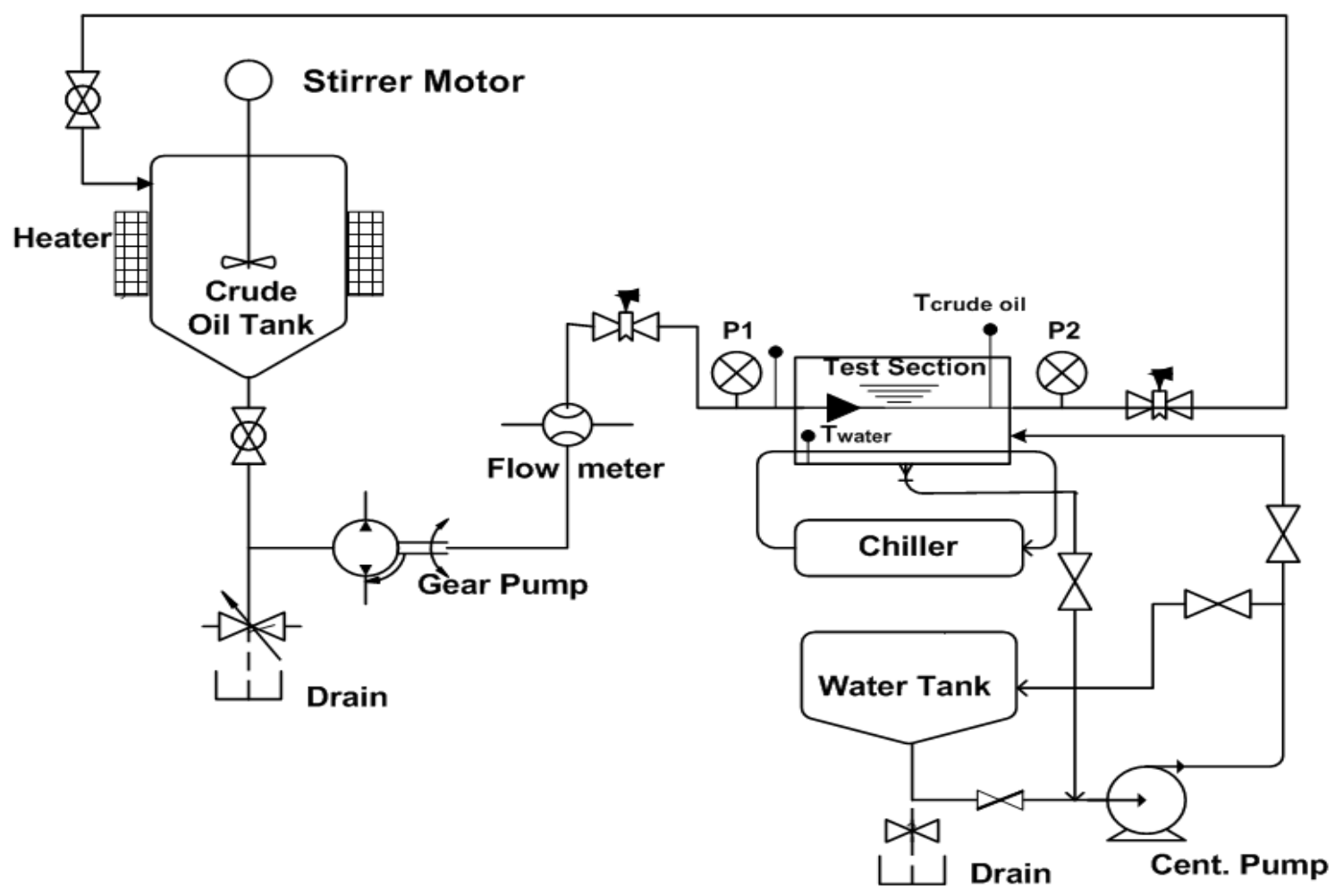

Figure 1. Experimental setup.

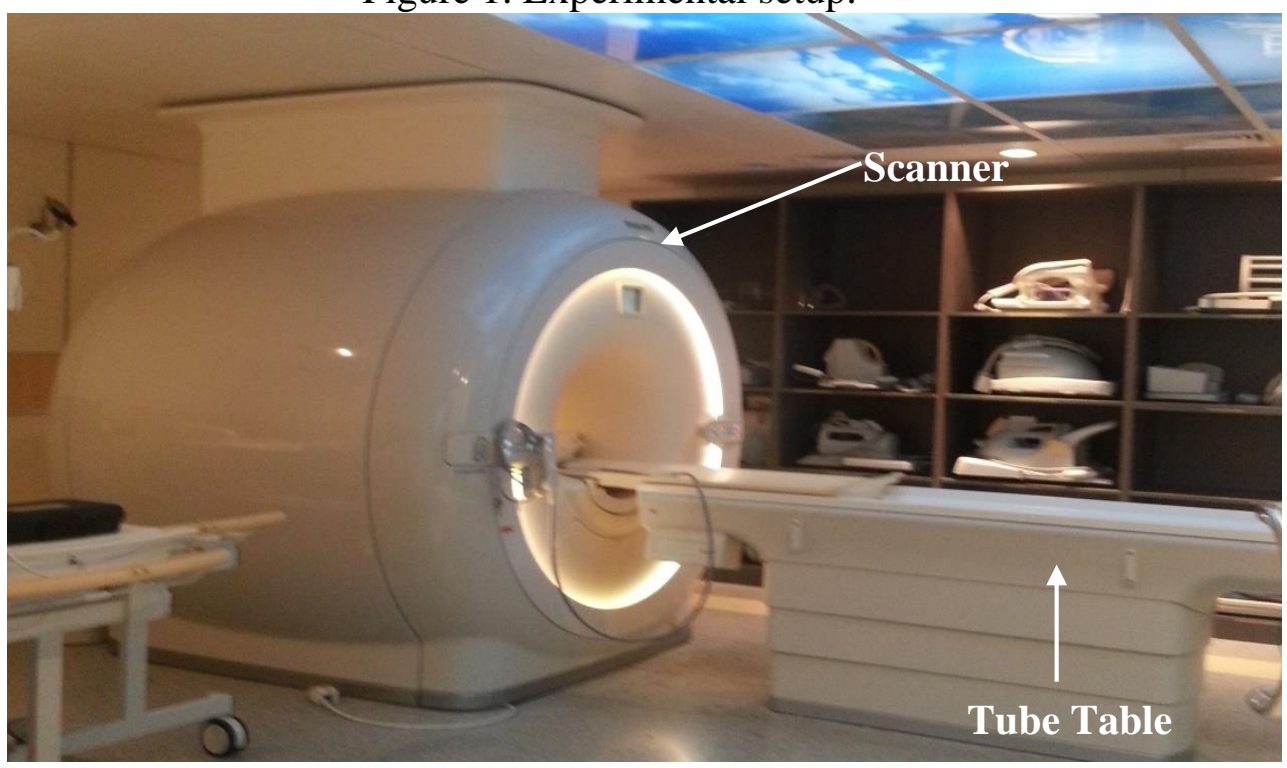

Figure 2. MRI used for the experiment. 
Table 1: Details of the initial temperature .

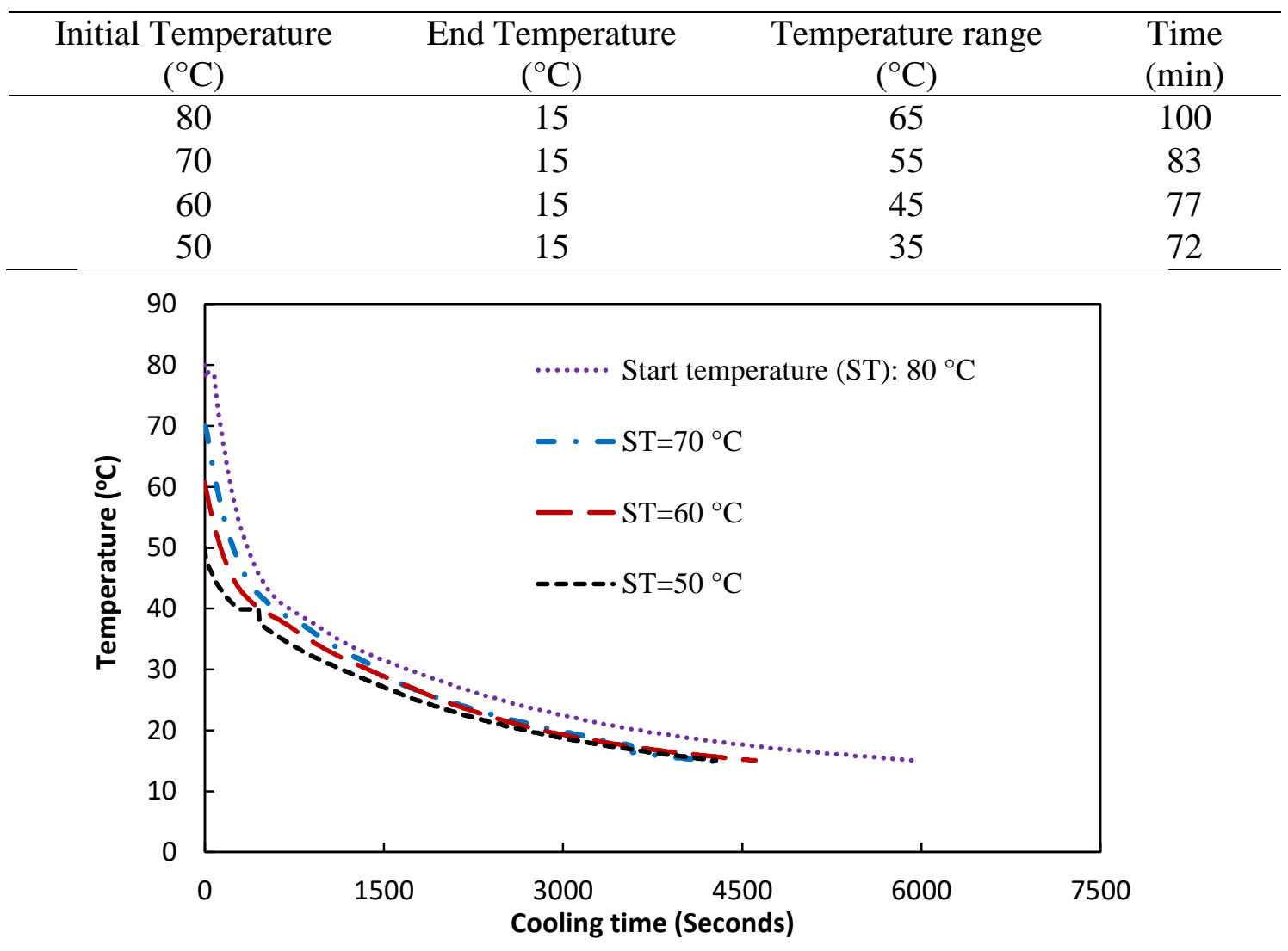

Figure 3. Profiles of initial temperature during cooling in the cold reservoir.

The amounts of heat transferred from the waxy crude oil and the transient convective heat transfer coefficient of waxy crude oil during phase changes and voids formation were calculated. The surrounding water and crude oil temperatures as a function of time were collected during the experiments. Figure 4 shows the cross section of the acrylic pipe carrying waxy crude oil and surrounded by flowing water for heat transfer analysis.

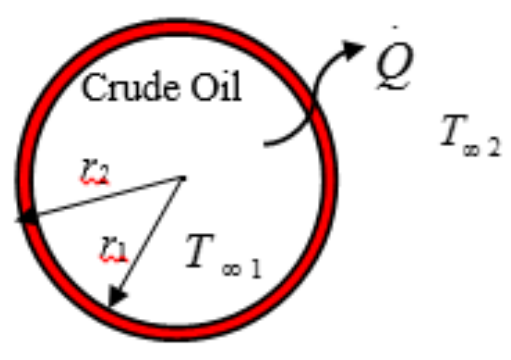

Figure 4. Cross sectional view of the acrylic pipe.

The heat loss from the statically cooled waxy crude oil was calculated using a thermodynamic equation as follows:

$$
\dot{Q}(t)=m c_{v} \Delta T(t)
$$


where $Q$ is the heat loss from the crude oil under cooling, $m$ is the mass of crude oil in the test section pipe, $c_{v}$ is the specific heat of waxy crude oil at constant volume and $\Delta T(t)$ is the temperature change of waxy crude oil over time.

The same amount of heat transferred to the cold surrounding water via convective and conduction mechanisms was also calculated as follows [13]:

$$
\dot{Q}(t)=\frac{T_{\infty 1}(t)-T_{\infty 2}(t)}{\frac{1}{h_{1}(t) 2 \pi r_{1} L}+\frac{1}{2 \pi k L} \ln \left(\frac{r_{2}}{r_{1}}\right)+\frac{1}{h_{2}(t) 2 \pi r_{2} L}}
$$

where $Q$ is the heat loss from the waxy crude oil under cooling, $T_{\infty 1}$ is the temperature of the waxy crude oil, $T_{\infty 2}$ is the water temperature, $\mathrm{h}_{1}$ is the heat transfer coefficient of crude oil, $\mathrm{h}_{2}$ is the heat transfer coefficient of water, $\mathrm{L}$ is the length of the test section pipe under cooling, $\mathrm{k}$ is the thermal conductivity of the acrylic pipe, and $r_{2}$ and $r_{1}$ are the outer and the inner radii of the pipe, respectively. The transient heat transfer coefficient of the waxy crude oil subjected to cooling was then calculated using Eqns (1) and (2).

\section{RESULTS AND DISCUSSION}

The effects of the initial temperature of the waxy crude oil on the intra-gel void formation in the wax-oil gel and the convective heat transfer coefficient of waxy crude oil while undergoing cooling were investigated. Figure 5 shows the transient heat transfer coefficient of waxy crude oil from the start of cooling. The heat transfer coefficient reduced significantly as the waxy crude oil temperature decreased owing to the heat loss to the cold surroundings. It reduced faster in the first 500 seconds of cooling in the Newtonian region prior to wax formation. It then became smaller after the wax appearance temperature owing to the wax crystal formation trapping some liquid oil within it, as reported [15]. Moreover, the heat transfer coefficient was almost similar after the deposition and gelation of waxes in the pipeline. The rapid heat transfer before the wax appearance temperature and the significant heat transfer changes before and after the pour point indicate the formation of intra-gel voids in the gelled waxy crude oil. Furthermore, the lower temperature drop of the waxy crude oil gel in the non-Newtonian region made the heat transfer coefficient smaller and almost similar afterwards [16].

The heat transfer rates of the waxy crude oil while undergoing cooling in the test section pipe were also investigated. Figure 6 shows the heat loss from the waxy crude oil to the cold surrounding water. The waxy crude oil had a higher heat transfer rate in its liquid state. The heat transfer rate was around $153 \mathrm{~W}$ when the temperature of waxy crude oil was $80{ }^{\circ} \mathrm{C}$. The heat transfer rate decreased to around $20 \mathrm{~W}$ at the waxy crude oil temperature of $38.5^{\circ} \mathrm{C}$, at which wax formation starts. The precipitation and deposition of waxes further reduced its heat transfer rate owing to the formation of wax crystals with some liquid crude oil entrapped within. The lower heat transfer rate below the pour point temperature of waxy crude oil could describe the formation of intra-gel voids within the gelled crude oil as there would be shrinkage experienced during the cooling. 


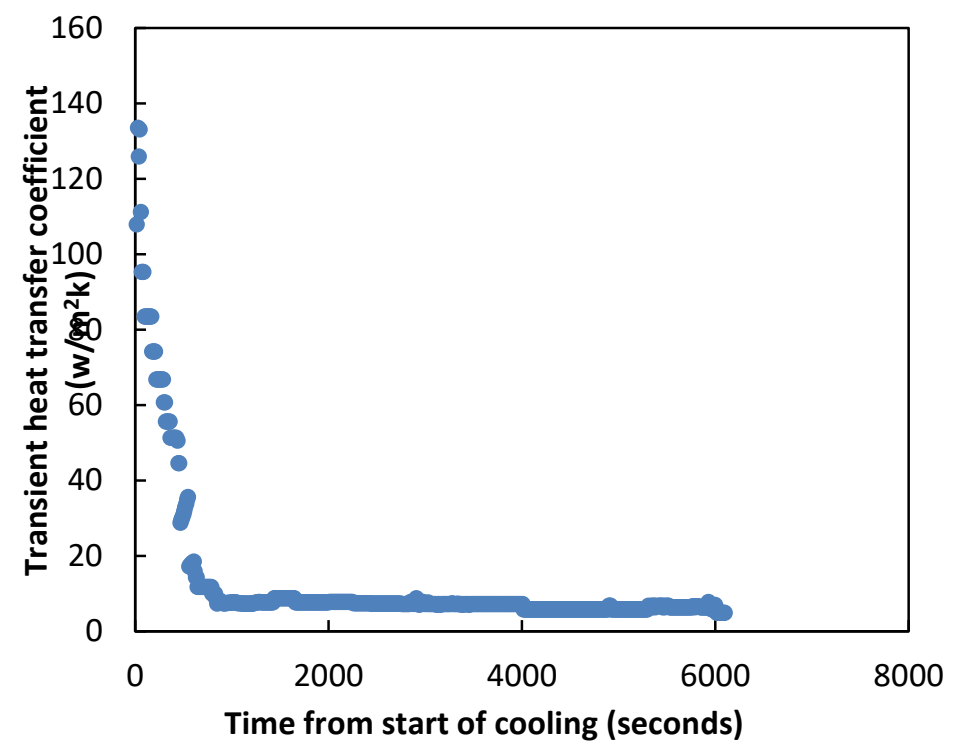

Figure 5. Transient heat transfer coefficient of waxy crude oil.

\section{Effects of Initial Temperature on Gas Voids}

The effects of varying the initial temperature of waxy crude oil on the formation of voids near the pipe wall and around the pipe core were investigated. Gas void formation near the pipe wall is shown in Figure 7(a). An initial temperature of $50{ }^{\circ} \mathrm{C}$ resulted in a relatively higher cross sectional void area over many parts of the scanned pipe. The void areas were observed to decrease for an initial temperature of $60{ }^{\circ} \mathrm{C}$ and increased slightly for a start temperature of $70^{\circ} \mathrm{C}$, forming an irregular void distribution along the pipeline and indicating the lower effects of initial temperature on void size as there was no wax crystal formation in the Newtonian region, as reported in [14].

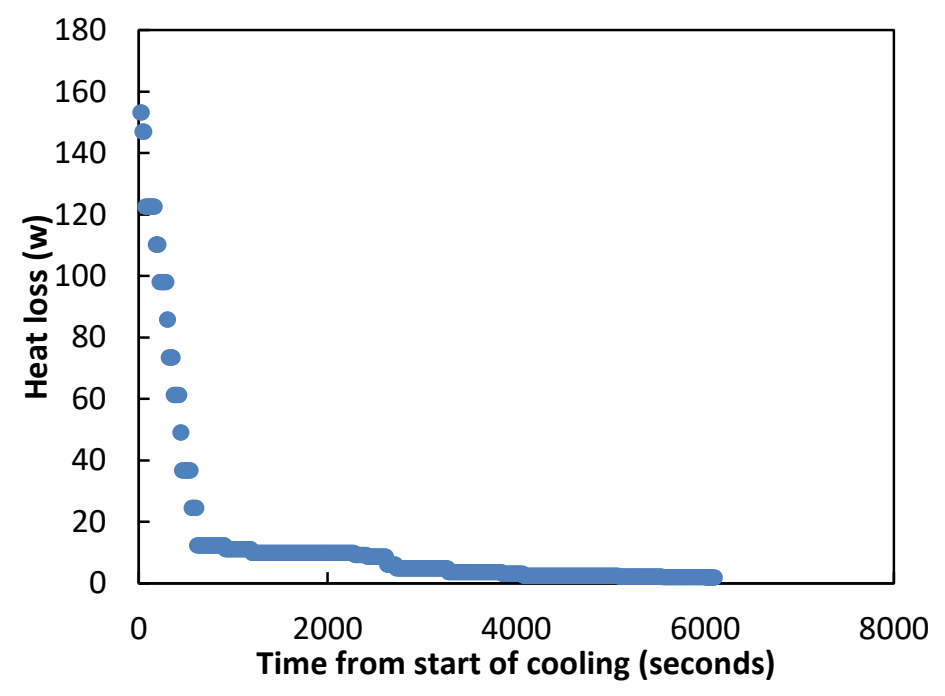

Figure 6. Heat loss from waxy crude oil while cooling.

Figure 7(b) shows the void area distribution around the pipe core. A start temperature of $60{ }^{\circ} \mathrm{C}$ produced higher cross sectional void areas over the outlet region of the scanned pipe ranging from $-40 \mathrm{~mm}$ to the outlet side compared to other initial 
temperatures, with a maximum void area of $14 \mathrm{~mm}^{2}$ at $40 \mathrm{~mm}$ from the midpoint of the pipe. The start temperature resulted in an irregular trend of intra-gel void formation around the pipe core. The minimum void areas were measured in the gelled crude oil cooled from the start temperature of $70{ }^{\circ} \mathrm{C}$, for which almost no void areas were detected from the middle to the outlet region of the scanned pipe.

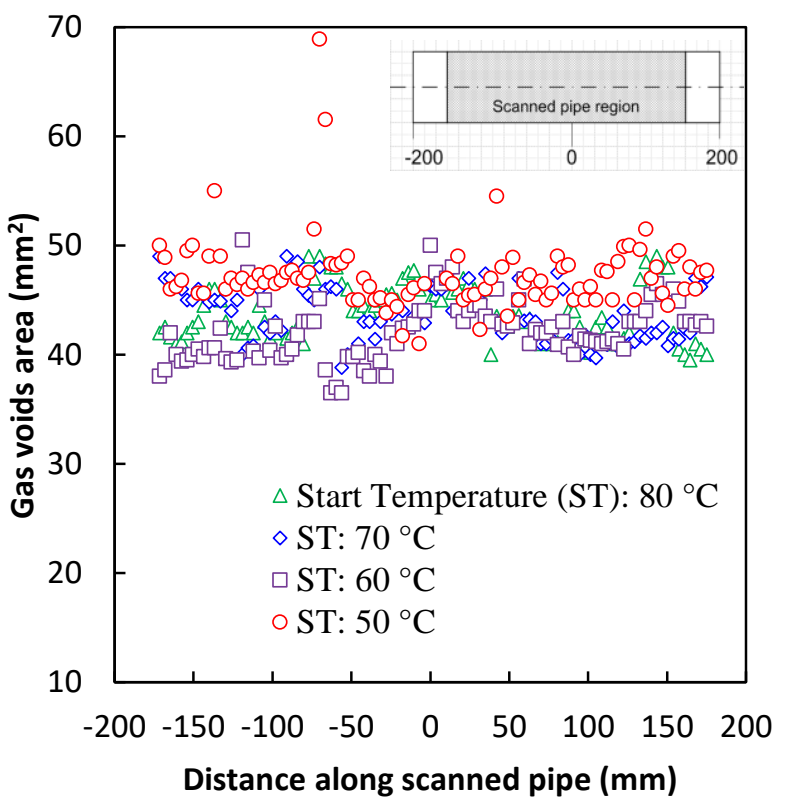

(a)

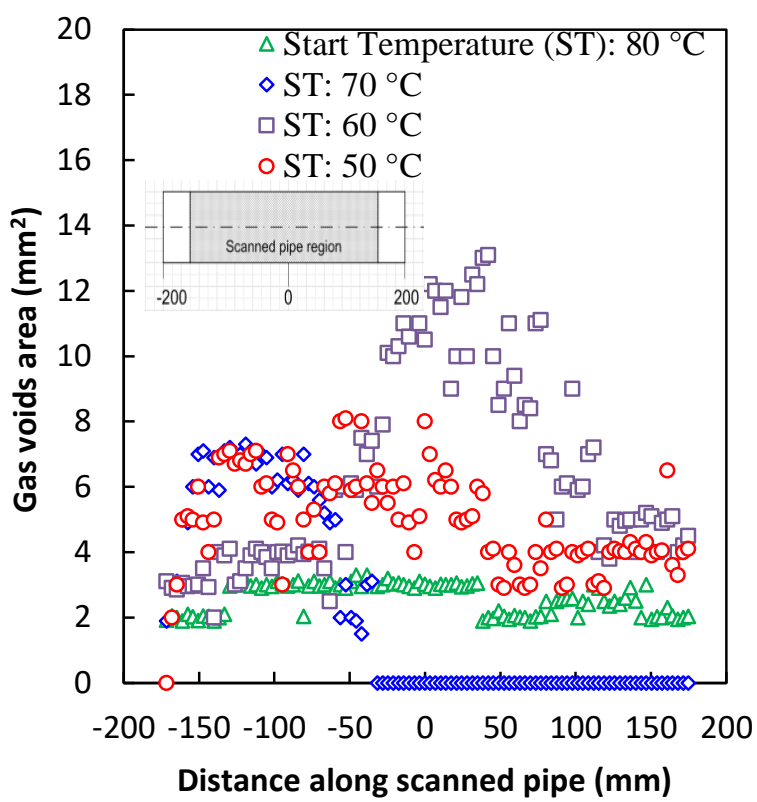

(b)

Figure 7. Gas void area (a) near pipe wall and (b) around pipe core.

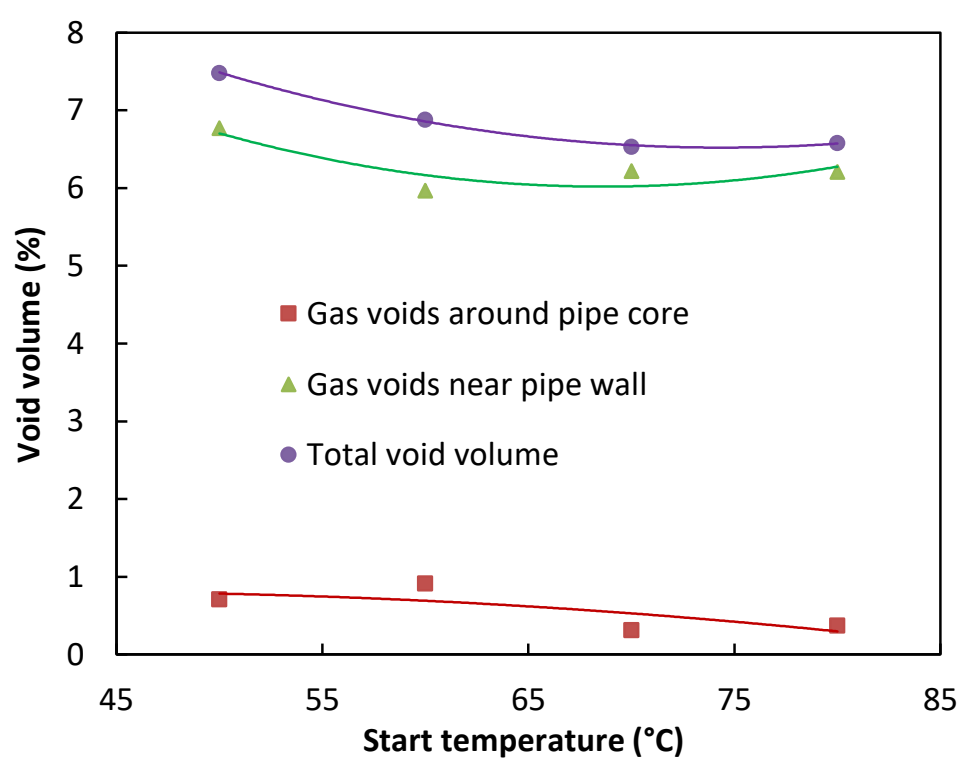

Figure 8. Percentage of void volume at different initial temperatures.

\section{Comparisons of Percentage of Void Volume}

The percentages of void volume around the pipe core, near the pipe wall and in the entire pipe region are shown in Figure 8 for comparisons. The trend of the total void volume was found to decrease as initial temperature increased, with a higher percentage of voids 
detected at $50{ }^{\circ} \mathrm{C}(7.48 \%)$ and a minimum void volume percentage of $6.58 \%$ in the gelled crude oil with initial temperature of $80^{\circ} \mathrm{C}$. A maximum void volume of $6.77 \%$ was again observed at the pipe wall in the sample cooled from an initial temperature of $50{ }^{\circ} \mathrm{C}$. However, a minimum void volume of $5.97 \%$ resulted when the initial temperature of the waxy crude oil was $60{ }^{\circ} \mathrm{C}$. In contrast to what is observed near the pipe wall and in the entire pipe, an initial temperature of $60^{\circ} \mathrm{C}$ resulted in a maximum void volume around the pipe core and the minimum void volume was observed at the initial temperature of $70{ }^{\circ} \mathrm{C}$, though the change in void volume was insignificant. In general, it was observed that the differences between void sizes for the different initial temperatures were insignificant, indicating the lower effect of start temperature on void formation. Moreover, the formation of intra-gel voids is eminent below the pour point temperature, as reported in [15-17].

\section{CONCLUSIONS}

The convective heat transfer coefficient of waxy crude oil and the effect of the initial temperature of waxy crude oil on intra-gel void formation were investigated experimentally. Waxy crude oil underwent cooling in the cold reservoir of the flow loop rig at a constant end temperature while varying the initial temperature. The heat transfer rate and the convective heat transfer coefficient of waxy crude oil were then calculated during the formation of voids in the wax-oil gel. It was observed that the heat transfer rate and the convective heat transfer coefficient of gelled crude oil below the wax appearance temperature were much lower than that of the Newtonian liquid crude oil. The convective heat transfer of gelled crude oil was also observed to be much lower than that for liquid crude oil owing to the wax crystals entrapping some liquid crude oil, after which the intra-gel void formation is eminent. Besides that, it was found that lower initial temperatures, which were higher than the wax appearance temperature, tended to form higher void volumes near the pipe wall and in the entire pipe with a maximum change in void volume of $0.9 \%$ observed between the maximum and minimum initial temperature tested. The insignificant influence of the initial temperature on void formation was also observed as the wax is liquid above the wax appearance temperature.

\section{ACKNOWLEDGEMENTS}

The authors would like to thank YUTP grant with project cost center no. 0153AA-A23 for the financial support and Hospital Universiti Sains Malaysia and its staff for providing access and assistance in the use of the MRI.

\section{REFERENCES}

[1] Chakhmakchev A, Rushworth P. Global overview of offshore oil and gas operations for 2005-2009. Offshore digital magazine. 05 January 2010.

[2] Sandrea R. An in-depth view of future world oil and gas supply-A production capacity model.Oil \& Journal Research Center. PennEnergy, 2010.

[3] Carnahan NF. Wax Properties and Behavior in Offshore Production and Transportation Systems.Presented at the Offshore Technology Conference, 30 April-3 May, Houston, Texas, USA, 2007.

[4] Chang C, Nguyen QD, Rønningsen HP. Isothermal start-up of pipeline transporting waxy crude oil. Journal of Non-Newtonian Fluid Mechanics. 1999;87:127-154. 
[5] Aiyejina A, Chakrabarti DP, Pilgrim A, Sastry MKS. Wax formation in oil pipelines: A critical review. International Journal of Multiphase Flow. 2011;37: 671-694.

[6] Economides MJ, Chaney GT. The Rheological Properties of Prudhoe Bay Oil and the Effects of a Prolonged Flow Interruption on its Flow Behavior. Society of Petroleum Engineers Journal. 1983;23:408-416.

[7] Golczynski TS, Niesen VG. Thermal Behavior During Restart of Ultra deepwater Flowlines.Presented at the SPE Annual Technical Conference and Exhibition, 29 September-2 October, San Antonio, Texas, USA, 2002.

[8] Luthi, IF. Waxy crude oil characterization and experimental study of the restart of a line blocked with gelled waxy crude. SPE Annual Technical Conference and Exhibition. 2013:5433-5443.

[9] Chala GT, Sulaiman SA, Japper-Jaafar A, Kamil Wan Abdullah WA, Mior Mokhtar MM. Gas void formation in statically cooled waxy crude oil. International Journal of Thermal Sciences. 2014;86:41-47.

[10] Phillips DA, Forsdyke IN, McCracken IR, Ravenscroft PD. Novel approaches to waxy crude restart: Part 1: Thermal shrinkage of waxy crude oil and the impact for pipeline restart. Journal of Petroleum Science and Engineering. 2011;77:237253.

[11] Chala GT, Sulaiman SA, Japper-Jaafar A, Kamil Wan Abdullah WA. Impacts of Cooling Rates on Voids in Waxy Crude Oil under Quiescent Cooling Mode Applied Mechanics and Materials. 2015;799-800:62-66.

[12] Chala GT, Sulaiman SA, Japper-Jaafar A, Kamil Wan Abdullah WA. Study on influence of flow rates on voids in waxy crude oil subjected to dynamic and static cooling. Journal of Mechanical Engineering and Sciences. 2015;9:1587-1594.

[13] Xing X., Dou D, Li Y, Wu C. Optimizing control parameters for crude pipeline preheating through numerical simulation. Applied Thermal Engineering. 2013; 51:890-898.

[14] Bergman TL, Incropera FP, Lavine AS. Fundamentals of heat and mass transfer: John Wiley \& Sons, 2011.

[15] Li H, Zhang J. A generalized model for predicting non-Newtonian viscosity of waxy crude as a function of temperature and precipitated wax. Fuel. 2003;82:1387-1397.

[16] Chen W, Zhao Z. Thermodynamic modeling of wax precipitation in crude oil. Chinese Journal of Chemical Engineering. 2006;14:685-689.

[17] Ahmadpour A, Sadeghy K, Maddah-Sadatieh S-R. The effect of a variable plastic viscosity on the restart problem of pipelines filled with gelled waxy crude oils. Journal of Non-Newtonian Fluid Mechanics. 2014;205:16-27.

[18] Hénaut I, Vincké O, Brucy F. Waxy Crude Oil Restart: Mechanical Properties of Gelled Oils. Presented at the SPE Annual Technical Conference and Exhibition, Houston, Texas, USA, 1999.

[19] Chala GT, Sulaiman SA, Japper-Jaafar A, Kamil Wan Abdullah WA. Effects of cooling regime on the formation of voids in statically cooled waxy crude oil. International Journal of Multiphase Flow. 2015;77:187-195.

[20] Shafquet A, Ismail I, Japper-Jaafar A, Sulaiman SA, Chala GT. Estimation of gas void formation in statically cooled waxy crude oil using online capacitance measurement. International Journal of Multiphase Flow. 2015;75:257-266. 